\title{
DISPERSION COEFFICIENT IN UNSATURATED SOIL EXPOSED TO EVAPORATION
}

\author{
HASHEM, M. ${ }^{1}$, A.A. MOHAMED ${ }^{2}$, K. WATANABE ${ }^{3}$, \\ A. NASHAAT ${ }^{4}$, M. ALI ${ }^{4}$, and A.K. ABDEL-LAH ${ }^{4}$ \\ ${ }^{1}$ Reseacher, Hydroscience and Geotechnology lab., Civil and Envir. Eng. Dept., Saitama University. (255 Shimo- \\ Okubo, Urawa-Shi, Satama 338-5870, Japan.) \\ ${ }^{2}$ Member of JSCE , Dr. of Eng., Hydroscience and Geotechnology lab., Civil and Envir. Eng. Dept., Saitama \\ University, Japan. \\ ${ }^{3}$ Member of JSCE, Ph. D., Prof., Environmental System, Graduate School of Science and Engineering, Saitama \\ University, Japan. \\ ${ }^{4}$ Civil Eng. Dept., Faculty of Eng., Assuit University, Egypt.
}

\begin{abstract}
Tracer experiment was carried out using a packed bed of fine sand, where groundwater flowed as a single phase under unsaturated conditions. A new apparatus with the new evaporation technique proposed by Mohamed et al. ${ }^{19}$ ) was used to create an upward movement (i.e. upward soil water potential gradient) to estimate the hydrodynamic dispersion coefficient (D). The concentration distribution of the sodium chloride $(\mathrm{NaCl})$ over the depth of the sand column at the end of the experiment could be measured using the electrical potential method. D could be determined by fitting an appropriate numerical solution of onedimensional Convection Dispersion Equation (CDE) to the measured vertical solute concentration through the depth of the unsaturated sand at the end of the experiment using Galerkin Finite Element Method (GFEM). A good agreement was found between the two series. The value of the estimated dispersivity is quite accurate and lies in the range $0.001-0.02 \mathrm{~m}$ which is suggested by many authors.
\end{abstract}

Key Words : Dispersion coefficient, unsaturated sand, evaporation.

\section{INTRODUCTION}

The movement of solutes through unsaturated soils is of importance in a number of environmental and agronomic problems ${ }^{1)}$. Because of the natural complexity of unsaturated flow, methods of predicting solute transport have relied largely on finite difference or finite element approximations of the governing equations ${ }^{2), 3), 4)}$. An analytical technique for evaluating solute movement in unsaturated zone was developed by Wilson and Gelhar ${ }^{1}$. Evaporation of water from the soil surface creates an upward soil water potential gradient; in response to this gradient, water is transported from deeper in the profile toward the soil surface where it evaporates and species dissolved in it concentrate or precipitate $^{5), 6)}$. In arid or semi-arid zones, the evaporation rate is quite high, so the upward movement of salts (when it is near the soil surface in the unsaturated zone) toward the soil surface causes the salinization of soil. Most of the previous researchers tried to estimate the dispersion coefficient (D) of solute transport in unsaturated soil, by applying an artificial rainfall on soil columns during downward solute movement (i.e. from top to bottom).

Hydrodynamic dispersion coefficient for the unsaturated zone has not been sufficiently investigated. The longitudinal dispersion in the unsaturated zone is greater than its value in the saturated zone ${ }^{7}$. Dispersion coefficient at relative high values of water saturation were investigated by Haga et al. ${ }^{8}$. Transport experiments of water and solutes during infiltration were carried out $^{9), 10), 11)}$. Solute dispersion coefficient as a function of the volumetric water content were investigated ${ }^{12), 13), 14)}$. Diffusion coefficients of Tritium in arid zone disposal sites was investigated by Smiles et $\mathrm{al}^{15)}$. Ogata and Banks ${ }^{16}$ 
carried out an experiment in unsaturated sand due to downward movement by infiltration and found that $\mathrm{D}$ values were ranged between ( 0.0065 $0.044) \mathrm{cm}^{2} / \mathrm{min}$ depend on the pore water velocity (V) values. Yule and Gardner ${ }^{y}$ carried out an experiment in unsaturated sand soil using artificial infiltration and found that $D=0.022$ $\mathrm{cm}^{2} / \mathrm{min}$ at $\mathrm{V}=0.069 \mathrm{~cm} / \mathrm{min}, \mathrm{D}=0.06 \mathrm{~cm}^{2} / \mathrm{min}$ at $\mathrm{V}=0.265 \mathrm{~cm} / \mathrm{min}$. Some others found that the value of $D$ in the heterogeneous soil depends on the flow direction. Huang et al. ${ }^{17}$ carried out laboratory tracer experiments in $12.50 \mathrm{~m}$ long horizontally placed soil columns during steady saturated water flow and they found that the flow direction effected the dispersivity. This implies that the value of $D$ estimated from downward groundwater flow differs from that one obtained from upward flow. Mohamed ${ }^{18)}$ has used the evaporation technique to estimate the dispersion coefficient (D) during the upward movement and they found that $D=0.13237 \times 10^{-5} \mathrm{~cm}^{2} / \mathrm{sec}$.

Although, the evaporation has a controlling influence in all hydrological processes and on many meteorological ones, its reliable estimates is quite difficult to obtain. In this study, we tried to create an upward groundwater flow using a new evaporation measuring technique. Also in this study, a new method for estimating the value of $D$ for unsaturated soil exposed to evaporation flux is presented.

\section{EVAPORATION MEASURING TECHINIQUE}

The measuring instrument mainly consists of three parts as in Fig. 1: a ventilated chamber, an evaporation rate measuring equipment developed by Mohamed et al. ${ }^{19)}$ and a soil box.

The ventilated chamber consists of a Perspex box (inner dimensions LxWxH: $1.20 \times 0.50 \times 0.80$ $\mathrm{m})$ lying on the soil box. The chamber is divided into three compartments in the longitudinal direction: the inlet compartment, the central compartment with six sellable instrument access opening in the top, and the outlet compartment. The main idea of this technique depends on covering some parts of the ground surface by a transparent sheet, injecting air from one side and extracting this air from the opposite side. The absolute humidity of the extracted air will be larger than that of the injected air and this due to the vapor comes out from the ground surface by evaporation and/or evapo-transpiration.

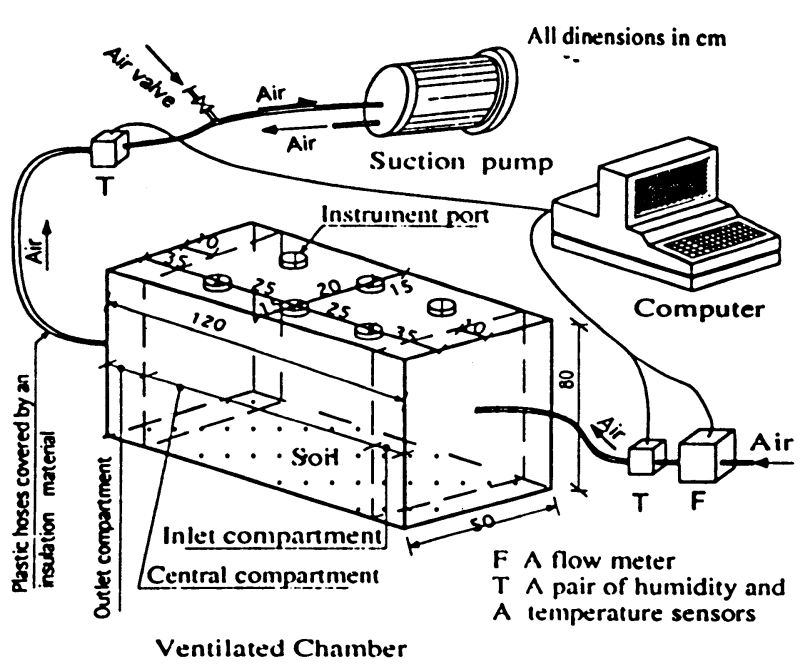

(A)

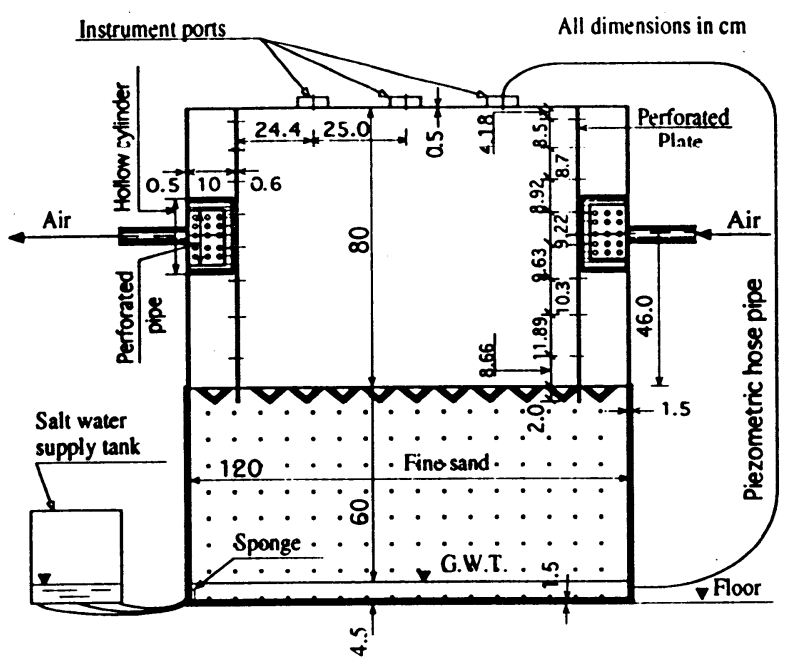

(B)

Fig. 1 Apparatus for upward solute movement (A) Evaporation measuring equipment. (B) Section through the ventilated chamber over the soil box

The evaporation rate from the ground surface which covered by the box can be calculated from the change of the absolute humidity of the air when it pass through the chamber, the area of the ground surface inside the chamber and the flow rate of the air.

The same technique that was proposed by Watanabe and Tsutsui ${ }^{20)}$ has been used to measure the evaporation rate. The air can be moved through the chamber by either a blower system or a suction system. In this study, the suction system has been used to avoid the pumping effects on both the temperature and relative humidity of the air.

The evaporation measurement apparatus was placed on a fine sand (standard sand) in a Perspex box (inner dimensions LxWxH: $1.20 \times 0.50 \times 0.63$ 
$\mathrm{m})$. The groundwater table could be established through two tubes connecting at a depth of 0.62 $\mathrm{m}$ lower the soil surface i.e. one $\mathrm{cm}$ from the box's bottom. A constant groundwater table could be maintained near the bottom of the soil column at $0.030 \mathrm{~m}$ from the bottom. So the depth of the unsaturated zone is $0.60 \mathrm{~m}$. The third tube serves as a piezometer. To compensate for the pressure difference between the evaporation measurement chamber and the atmosphere, the open end of the piezometer tube was connected to the measurement chamber.

\section{MATERIALS AND SOLUTE}

In this study a fine sand (Toyoura standard sand) has been used, the mean grain size diameter is $0.19 \mathrm{~mm}$, a saturated hydraulic conductivity is $0.29 \mathrm{~cm} / \mathrm{s}$, the specific gravity is $2630 \mathrm{~kg} / \mathrm{m}^{3}$, the dry bulk density is $1420 \mathrm{~kg} / \mathrm{m}^{3}$, and the porosity is $44.5 \%$. The sand was cleaned and washed several times before using in this work until the electrical potential of the washing water equal to the electrical potential of the clean water. Sodium Chloride used as a tracer whenever density is not a critical factor. Also, $\mathrm{NaCl}$ was used as a tracer because it is a conservative tracer and used in numerous laboratory experiments.

\section{EXPERIMENTAL WORK}

A tracer laboratory experiment was carried out for 90.0 days. Sodium Chloride solutions $(19.0 \mathrm{~g} / 1$ of $\mathrm{NaCl}$ ) were supplied through the groundwater supply tank. A groundwater table was maintained at $0.60 \mathrm{~m}$ from the soil surface and $0.030 \mathrm{~m}$ from the box bottom by adding solution to the tank continuously to keep the groundwater table (G.W.T.) at a constant level. At the end of the experiment, two adjacent soil samples were taken at several levels over the height of the sand column. One sample was used to determine the gravitational water content $(\omega)$ while the other sample used for measuring the $\mathrm{NaCl}$ concentration. The electrical potential method was used for estimating the solute concentration because of the electrolytic characteristic of the $\mathrm{NaCl}$ as a tracer.

\section{MATHEMATICAL BACKGROUND (1) Evaporation rate}

To calculate the evaporation rate, we convert the measured relative humidities of the air entering and leaving the evaporation measurement chamber according to Brutsaert ${ }^{21)}$.

$$
\begin{gathered}
\mathrm{e}_{\mathrm{a}}^{*}=101325 \exp \left(13.3185 \mathrm{t}_{\mathrm{Ra}}-1.9760 \mathrm{t}^{2}{ }_{\mathrm{Ra}}\right. \\
-0.6445 \mathrm{t}^{3}{ }_{\mathrm{Ra}}-0.1229 \mathrm{t}^{4}{ }_{\mathrm{Ra}} \\
\mathrm{e}_{\mathrm{a}}=\frac{\mathrm{e}_{\mathrm{a}}^{*} \mathrm{H}_{\mathrm{r}}}{100} \\
\beta=\frac{0.622 \times 10^{-3} \mathrm{e}_{\mathrm{a}}}{\mathrm{RT}_{\mathrm{a}}}
\end{gathered}
$$

where $e_{a}^{*}$ is the saturated vapor pressure of the air $(\mathrm{Pa})$ at air temperature $\mathrm{T}_{\mathrm{a}}(\mathrm{K})$, $t_{R a}=1-\left(373.15 / T_{a}\right), \quad e_{a}$ is the vapor pressure $(\mathrm{Pa}), \mathrm{H}_{\mathrm{r}}$ is the relative air humidity (\%), $\beta$ is the absolute air humidity $\left(\mathrm{Mg} / \mathrm{m}^{3}\right), \mathrm{R}$ is the gas constant for dry air $\left(287.04 \mathrm{~J} \mathrm{~kg}^{-1} \mathrm{~K}^{-1}\right)$, and the constant 0.622 is the ratio of the molecular weights of water dry air. The evaporation rate can be calculated as:

$$
E=86.4 \times 10^{3} \frac{Q\left(\beta_{\text {out }}-\beta_{\text {in }}\right)}{\rho A}
$$

where $\mathrm{E}$ is the evaporation rate ( $\mathrm{mm} /$ day), $\mathrm{Q}$ is the volumetric flow rate of the air $(1 / \mathrm{s}), \beta_{\text {out }}$ and $\beta_{\text {in }}$ are the absolute humidities $\left(\mathrm{Mg} / \mathrm{m}^{3}\right)$ of the air after and before passing through the chamber respectively, $\rho$ is the density of the water $\left(\mathrm{Mg} / \mathrm{m}^{3}\right)$, and $A$ is the soil surface area $\left(\mathrm{m}^{2}\right)$.

\section{(2) Unsaturated groundwater flow}

The soil water movement in the unsaturated zone can be calculated by solving the one dimension classical Richards' equation defined as:

$$
\begin{aligned}
C(\theta) \frac{\partial h}{\partial t} & =\frac{\partial}{\partial z}\left\{K_{0} r(\theta) \frac{\partial h}{\partial z} \pm q_{1}\right\} \\
h & =z+\psi
\end{aligned}
$$

where $\theta$ is the saturation, $C(\theta)$ is the specific water capacity $\left(\mathrm{m}^{-1}\right), \mathrm{K}_{\mathrm{o}}$ is the saturated hydraulic conductivity $(\mathrm{m} / \mathrm{s}), \mathrm{r}(\boldsymbol{\theta})$ is the relative hydraulic conductivity, $q_{1}$ is the sink or source term $\left(s^{-1}\right), h$ is the total head $(\mathrm{m}), \mathrm{t}$ is the time (s), $\mathrm{z}$ is the 


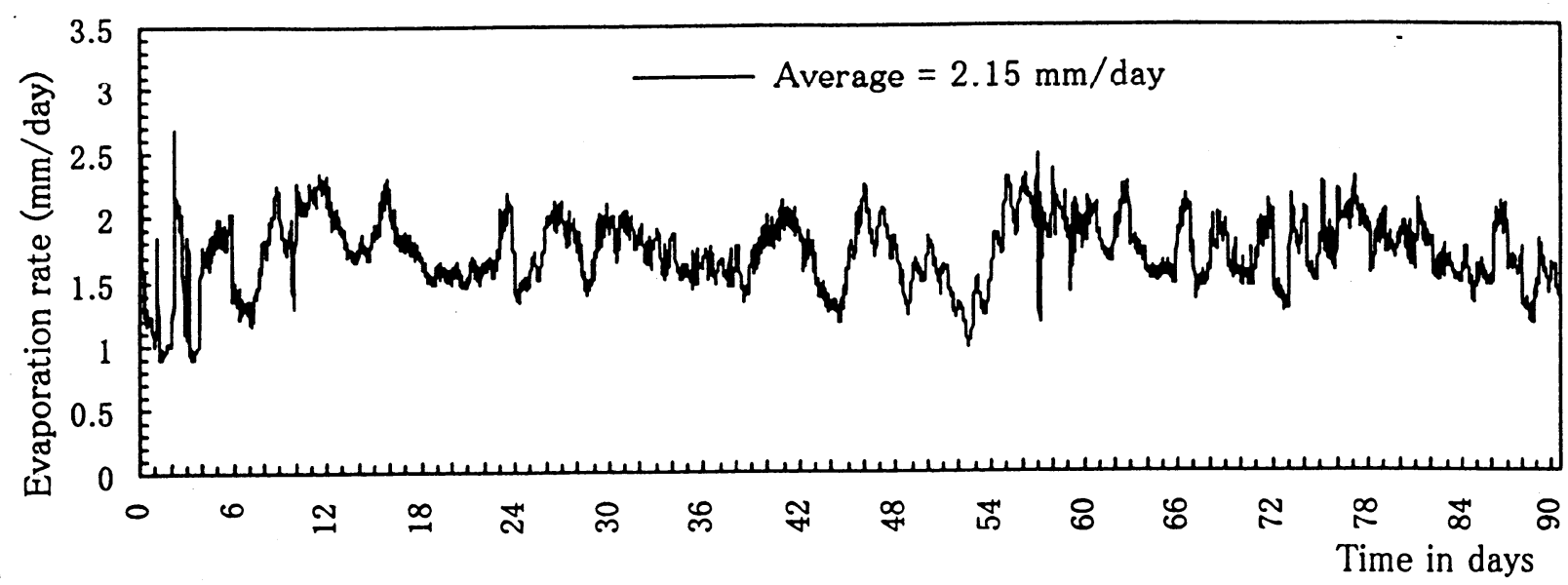

Fig.2 Measured evaporation rate distribution during the experiment.

height from a reference level (m), and $\psi$ is the capillary pressure head (m). Equation (5) can be solved numerically if the boundary and initial conditions of the flow and the properties of the soil are defined. Both of the specific capacity $C(\theta)$ and the relative hydraulic conductivity $r(\theta)$ may be defined as a function of the capillary pressure head $(\psi)$ using the van-Genuchten's model ${ }^{22)}$ as follows:

$$
\begin{gathered}
\theta_{\mathrm{e}}=\frac{\theta-\theta_{\mathrm{r}}}{\theta_{\mathrm{s}}-\theta_{\mathrm{r}}} \quad\left(1 \geq \theta_{\mathrm{e}} \geq 0\right) \\
\theta_{\mathrm{e}}=\left(1+|\alpha \psi|^{\mathrm{n}}\right)^{\mathrm{m}} \quad(\alpha>0) \\
\mathrm{n}=\frac{1}{1-\mathrm{m}} \\
\mathrm{r}(\theta)=\theta_{\mathrm{e}}^{\mathrm{L}}\left(1-\left(1-\theta_{\mathrm{e}}{ }^{1 / \mathrm{m}}\right)^{\mathrm{m}}\right)^{2} \\
\mathrm{C}(\theta)=\alpha(\mathrm{n}-1)\left(\theta_{\mathrm{s}}-\theta_{\mathrm{r}}\right) \theta_{\mathrm{e}}{ }^{1 / \mathrm{m}}\left(1-\theta_{\mathrm{e}}{ }^{1 / \mathrm{m}}\right)^{\mathrm{m}}
\end{gathered}
$$

where $\theta_{\mathrm{s}}$ and $\theta_{\mathrm{r}}$ are the maximum and residual saturation ratio, $\alpha$ and $m$ are the van-Genuchten's parameters. $\mathrm{L}$ is the a pore connectivity parameter. $\mathrm{L}$ in hydraulic conductivity function was estimated by Mualem ${ }^{23)}$ to be 0.5 as an average value for many soils.

\section{(3) Solute transport model}

For modeling solute transport in unsaturated zone the Convection-Dispersion Equation (CDE) is the foundation upon which numerous mathematical analysis of solute transport in porous media have been based ${ }^{24)}$ and it was used by many authors ${ }^{25), 26), 27)}$. The one-dimensional $\mathrm{CDE}$ is:

$$
\frac{\partial \theta_{v} \mathrm{C}}{\partial \mathrm{t}}=\frac{\partial}{\partial \mathrm{z}}\left(\mathrm{D} \theta_{\mathrm{v}} \frac{\partial \mathrm{C}}{\partial \mathrm{z}}\right)-\frac{\partial}{\partial \mathrm{z}}(\mathrm{qC})
$$

where $C$ is the solute concentration $\left[\mathrm{g} / \mathrm{m}^{3}\right], \theta_{v}$ is the volumetric water content $\left(\mathrm{m}^{3} / \mathrm{m}^{3}\right)$, D is the hydrodynamic dispersion coefficient $\left[\mathrm{m}^{2} / \mathrm{s}\right]$, which depends upon the average pore-water velocity $\mathrm{V}=\mathrm{q} / \theta_{\mathrm{v}}[\mathrm{m} / \mathrm{s}], \mathrm{t}$ is the time $(\mathrm{s})$, and $\mathrm{z}$ the height from a reference level $(\mathrm{m})$.

Equations 5 and 12 were solved simultaneously by Galerkin Finite Element Method (GFEM). At any time step Eq. 5 was solved numerically under the defined boundary conditions with the estimated unsaturated hydraulic properties to get the distribution of the pore water velocity (V). The resulted profile of $\mathrm{V}$ was used directly in the numerical solution of CDE simultaneously.

\section{RESULTS AND ANALYSIS}

\section{(1) Evaporation measurement and unsaturated properties}

During 90.0 days of measurements the values of input and output temperature of the air were recorded (input average value $=24.98^{\circ} \mathrm{C}$ and output average value $=25.1^{\circ} \mathrm{C}$ ) and the relative 


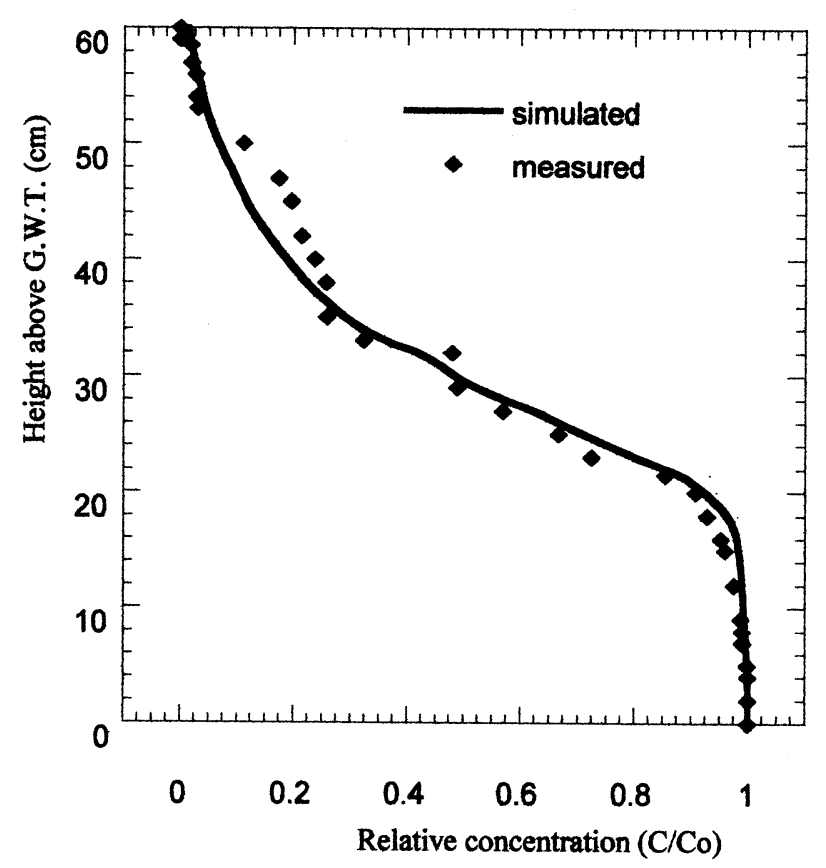

Fig. 3 Measured and simulated solute concentration profiles over the height of the column at the end of the experiment.

humidity of this air which passing through the ventilated chamber were recorded, also (input average value $=12.419 \%$ and output average value $=14.658 \%$ ). The volumetric flow rate of the air was constant with a value of $600.0 \mathrm{l} / \mathrm{s}$. According to the values of the volumetric flow rate of the air, the absolute humidity of the inflow and outflow air, and the top surface area of the soil box, the values of evaporation rate were calculated every $15.0 \mathrm{~min}$. as a time interval. The average value of the evaporation rate through the whole period of the experiment was $2.15 \mathrm{~mm} /$ day as in Fig. 2. We (the authors) numerically solved Richards' equation using GFEM. The soil hydraulic properties were described by vanGenuchten $^{22)}$ parameters and methods of Watanabe et al. ${ }^{28)}$ and Abozeid et al. ${ }^{29)}$ were used for estimation of the parameters $\theta_{\mathrm{s},} \theta_{\mathrm{r}, \mathrm{m}}$, and $\alpha$. The average value of the evaporation rate was $2.15 \mathrm{~mm} /$ day and this value was used as upper boundary condition in the numerical simulation and the lower boundary condition is a pressure head equal to zero at the groundwater table. The calculated parameters were $\theta_{\mathrm{s}}=0.999, \theta_{\mathrm{r}}=0.04$, $\alpha=0.03587 \mathrm{~cm}^{-1}$, and $\mathrm{m}=0.74191$ and these values were used also during the numerical simulation of the (CDE) using GFEM.

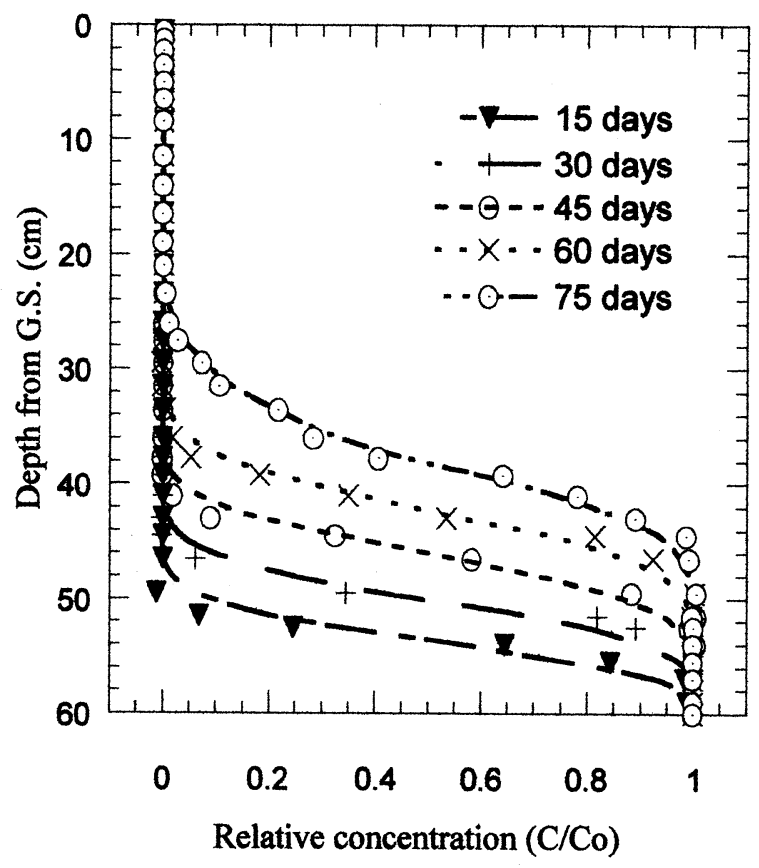

Fig. 4 Simulated solute distribution over the height of the column with the time interval of 15.0 days.

\section{(2) Solute concentration and dispersivity}

The movement of tracer ion $\left(\mathrm{Cl}^{-}\right)$in an unsaturated sandy soil can be analyzed by one- dimensional CDE. The solute distribution over the depth of the sand column was measured experimentally and simulated numerically. A good agreement between the measured and simulated values was found as in Fig. 3. This implies the applicability of CDE to describe solute transport in unsaturated zone under the experimental condition. The dispersivity $(\zeta=\mathrm{D} / \mathrm{V})$ value has traditionally been considered as a characteristic of the entire medium $^{30)}$, usually of order of 0.001 to $0.02 \mathrm{~m}$ for repacked homogenous soil columns ${ }^{31,32)}$. From the numerical simulation of the experimental results, the dispersion coefficient (D) was found to be $1.2 \times 10^{-9} \mathrm{~m}^{2} / \mathrm{sec}$. The average value of the dispersivity was $0.001335 \mathrm{~m}$. This implies that the dispersivity value lies in the suggested range by the previous authors. The distribution of the solute with the height of the sand column was estimated with 15.0 days interval time as in Fig. 4.

\section{CONCLUSIONS}

From this study of solute transport in a fine 
sand column exposed to evaporation from its upper surface, we can conclude that: the solute distribution could be measured experimentally and simulated numerically, and a good agreement between those values were found. The convection-dispersion equation can be used in the simulation of solute transport in unsaturated zone, provided that the dispersion coefficient is around 20 times of its value under comparable saturated flow. The dispersivity value was agreed with the suggested values as observed by Fried, Freeze and Cherry ${ }^{31,32)}$

\section{REFERENCES}

1) Wilson J.L., and Gelhar L.W.: Analysis of longitudinal dispersion in Unsaturated Flow, 1. The Analytical Method.' Water Resour. Res., 17(1), 122-130, 1981.

2) Warrick, A.W., Bigger J.W., and Nielsen D.R. Simultaneous solute and water transfer for an unsaturated soil, Water Resour. Res. 7(5), 1261-1225, 1971

3) Bresler E.: Simultaneous transport of solutes and water under transient unsaturated flow conditions, Water Resour. Res., 9(4), 975-986, 1972.

4) Gaudet J.P., Vachaud G., and Wierenga P.: Solute transfer with exchange between mobile and stagnant water, through unsaturated sand, Soil Sci. Soc. Am. J., 41(4),665-673, 1977.

5) Zawislanski, Peter T., Tokunaga Tetsu K., Benson Sally M., Oldfather Joan M., and Narasimhan T. N.: Bare Soil Evaporation and Solute Movement in Selenium Contaminated Soils of Kesterson Reservoir, J. Environ. Qual. 21:447-457, 1992.

6) Hashem M., Mohamed A.A., Watanabe K., Nashaat A., Ali M., and Abdel-Lah A.K.: An investigation of solute transport through unsaturated soil exposed to evaporation, Proc., 54 ${ }^{\text {th }}$ Annual National Conf., JSCE, Horishima, Japan, 1999.

7) Yule, D.F. and Gardner W.R.: Longitudinal and transverse dispersion coefficients in Unsaturated plainfield sand, Water Resour. Res, 14(4), 582-588, 1978.

8) Haga D., Niibori Y., And Chida T.: Hydrodynamic dispersion and mass transfer in unsaturated flow, Water Resour. Res., 35(4), 1065-1077, 1999.

9) Smiles D.E., and Gardiner B.N.: Hydrodynamic dispersion during unsteady, unsaturated water flow in a clay soil, Soil Sci. Soc. Am. J., 46, 9-14, 1982.

10) Bond W.G., and Philips I.R.: Cation exchange isotherms obtained with batch and miscible displacement technique, Water Resour. Res. 26(10), 2475-2481, 1990.

11) De Smidt F. and Wiener P.J.: Approximate analytical solution for solute flow during infiltration and redistribution, Soil Sci. Soc. Am. J., 42, 407-412, 1978.

12) Smiles D.E., Philip J.R., Knight J.H., and Elrick D.E.: Hydrodynamic dispersion during absorption of water by soil, Soil Sci. Soc. Am. J., 42, 229-234, 1978.

13) White, I., Smiles D.E. and Perroux K.M.: Absorption of water by soil: The constant flux boundary condition, Soil Sci. Soc. Am. J., 43, 659-664, 1979.
14) Laryea K.B., E.Elrick D., and Robin M.J.L.: Hydrodynamic dispersion involving cationic absorption during unsaturated, transient water flow in soil, Soil Sci. Soc. Am. J., 46, 667-671, 1982.

15) Smiles D.E., Gardner W.R., and Schulz R.K.: Diffusion of tritium in arid disposal sites, Water Resour. Res., 31(6), 1483-1488, 1995.

16) Ogata A., and Banks R.B.: A solution of the differential equation of longitudinal dispersion in porous media, $\mathrm{U}$. S. Geol. Surv. Prof. Pap., 411-A, 1961.

17) Huang K., Toride N., and Van Genuchten M.Th.: Experimental investigation of solute transport in large, homogenous and heterogeneous saturated soil columns, Transport in Porous media., 18, 283-302, 1995.

18) Mohamed A.A.: An investigation of pollutants migration in shallow underground due to evaporation, Ph. D. Dissertation, Civil and Environmental Engg. Dept., Saitama University, Japan, 1998.

19) Mohamed, A.A., Watanabe K, and Sasaki T.: Ventilated Chamber system for continuous recording of both the evaporation rate and the heat balance at the bare soil surface, Journal of Groundwater Hydrology. 40(2): 185202, 1998.

20) Watanabe K., and Tsutsui Y.: A new equipment used for measuring evaporation in a field, Proc. $7^{\text {th }}$ Cong., IAEG: 309-313, 1994.

21) Brutseart, W.: Evaporation into the atmosphere, Kluwer Academic Publisher, 1982.

22) Van Genuchten, M.TH.: A closed form equation for predicting the hydraulic conductivity of unsaturated soils, Soil Sci. Soc. Am. J., 40, 82-898, 1980.

23) Mualem, Y.: A new model for predicting the hydraulic conductivity of unsaturated porous media, Water Resour. Res. 12: 513-522, 1976.

24) Parker J.C., and van Genuchten M.Th.: Flux-Averaged and Volume-Averaged Concentrations in Continuum Approaches to Solute Transport, Water Resour. Res. 20 : 866-872, 1984.

25) Porro, I., Wierenga P.J., and Hills R.G.: Solute transport through large uniform and layered soil columns, Water Resour. Res. 29: 1321-1330, 1993.

26) Beven, K.J., Henderson D.E., and Reeves A.D.: Dispersion parameters for undisturbed partially saturated soil, J. Hydrol. (Amsterdam) 143:19-43, 1993.

27) Jury W.A., and Fluhler H.: Transport of chemicals through soil: Mechanisms, models and field applications, Adv. Agron. 47: 141-201, 1992.

28) Watanabe, K., Sasaki T., Hoshino Y. , and Hamada S.: In-situ and laboratory tests for estimating the hydraulic properties of unsaturated rock, Proc. $8^{\text {th }}$ int. Cong. On rock Mech., Tokyo, Japan, 725-728, 1995.

29) Abozeid G., Watanabe K., Ashour M., Nashaat A., and Ali M.: In situ determination of the hydraulic properties of unsaturated soil, Proc., $51^{\text {th }}$ Annual National Conf., JSCE, Nagoya, Japan, 1996.

30) Bear J.: Dynamics of fluids in porous media, Elsevier, New York, 1972.

31) Fried J. J.: Groundwater pollution, Elsevier, New York, 1975.

32) Freeze R.A., and Cherry J.A.: Groundwater, PrenticeHall, Englewood Cliffs, 1979.

(Received September 30,1999) 